Bangladesh J. Pl. Breed. Genet., 24(2): 09-18, 2011

\title{
GENOTYPE-LOCATION INTERACTION OF INDICA RICE USING AMMI MODEL
}

\author{
M. J. Hasan, M. U. Kulsum, M. S. Hossain ${ }^{1}$, M. M. Billah² and A. Ansari \\ Hybrid Rice Section \\ Bangladesh Rice Research Institute \\ Joybdebpur, Gazipur 1701, Bangladesh
}

\begin{abstract}
Phenotypic stability of 12 rice genotypes for plant height, days to maturity and yield were assessed at five different locations through regression and deviation from regression using Additive Main Effect and Multiplicative Interaction (AMMI) model. The result showed highly significant genotypic and $\mathrm{G} \times \mathrm{E}$ interaction. The $\mathrm{G} \times \mathrm{E}$ interaction influenced the relative ranking of the genotypes tested, BR1A/BR827R, Teea, BRRI dhan33 and Mayna showed low interaction effect with score nearest to zero with above average yield. While two genotypes BRRI hybrid dhan4 and Heera995 exhibited high positive interaction effect, gave mean grain yield around 5 ton/ha and was better suited to favorable environments. Similarly AMMI characterized the environments and identified Satkhira as a favorable environment for the better expression of the trait studied.
\end{abstract}

Key words: GEI, RCBD, IPCA Score, biplot analysis

\section{INTRODUCTION}

Bangladesh Rice Research Institute has so far developed 58 high yielding modern rice varieties for different ecosystems. Among them four are hybrids and named as BRRI hybrid dhan1, BRRI hybrid dhan2, BRRI hybrid dhan3 and BRRI hybrid dhan4. However, many of these varieties do not seen to exist in the farmer's field since they show instability with regards to productivity over a wide range of environment. Multi-location testing of genotypes provides an opportunity to the plant breeders to identify the adaptability of a genotype to a particular environment and also stability of the genotype over different environments. Stability in grain yield is one of the most desirable traits of a genotype to be released as a variety for commercial cultivation. The developed varieties should adapt to a wide range of target environments, is the eventual goal of plant breeders. Hence, pattern of response of genotypes is studied by the plant breeders for testing genotypes in different environments to assess the genotype $\mathrm{x}$ environment $(\mathrm{G} \times \mathrm{E})$ interaction. To estimate the level of interaction of genotypes to environments and to eliminate as much as possible the unexplainable and extraneous variability contained in the data, several statistical techniques have been developed to describe G x E interaction and measure the stability of genotypes. Detailed study on current statistics used to test and measure genotype stability has given by Lin et al. (1986), Piepho (1999) and Laxmi and Gupta (2000).

${ }^{1}$ LGED, Itna, Kishoregonj, Bangladesh, ${ }^{2}$ Bangladesh Agricultural Research Institute, Gazipur 1701, Bangladesh. 
Since, G x E interaction is naturally multivariate, the Additive Main effects and Multiplicative Interaction (AMMI) model offers appropriate statistical analysis of yield trials that may have a G x E interaction (Zobel et al., 1998). Keeping the above in view, the present study was under taken to assess the extent of $\mathrm{G} \times \mathrm{E}$ interaction and to select the stable genotypes of hybrid rice over the environments.

\section{MATERIALS AND METHODS}

The experiment was conducted during the main rainy season (T. Aman) of 2008 at Gazipur, Satkhira, Faridpur, Jamalpur and Rajshahi locations. Nine rice hybrids along with BRRI dhan31, BRRI dhan33 and BRRI dhan39 as check were included in the study. The experiment was laid out in Randomized Complete Block Design (RCBD) with three replications in a plot size of $30 \mathrm{~m}^{2}$ at spacing of $20 \times 15 \mathrm{~cm}^{2}$. Twenty one days old seedlings were transplanted with one to two seedlings per hill. Fertilizers were applied @ 150: 100: 70: 60: $10 \mathrm{~kg} / \mathrm{ha}$, urea, TSP, MP, Gypsum and ZnSO4. Nitrogen was applied in three split applications @ 50: 25: $25 \mathrm{~kg} / \mathrm{ha}$ at 15 days interval each after transplanting, maximum tillering and panicle initiation stage. Total amount of TSP, MP, Gypsum and $\mathrm{ZnSO} 4$ were applied at final land preparation. Standard cultural practices were followed in all the locations to raise a good crop. Plant height $(\mathrm{cm})$, growth duration (days) and plot yield (t/ha) were recorded at maturity by harvesting whole plot and adjusted at $14 \%$ moisture content.

The analysis of variance (ANOVA) was used and the GE interaction was estimated by the AMMI model (Zobel et al., 1998). Thus, the mean response of the genotype $i$ in environment $j(Y i j)$ is modeled by: $Y i j=\mu+g i+a j+\mathrm{E} 8 k(i k$ " $j k+D i j+$ $e i j$; where $\mu$ is a common constant to the responses (normally the general mean); gi is the fixed effect of genotype $i(i=1,2, \ldots, \mathrm{g}) ; a j$ is the fixed effects of environment $j(j=1$, $2, \ldots, a)$; E8k ( $i k$ " $j k$ is the fixed significant effect or pattern of the specific interaction of the genotype $i$ with environment $j$ (gaij), where, $8 k$ is the k-th singular value (scalar), ( $i k$ and " $j k$ are the correspondent elements, associated to $8 k$, of the singular vectors (rows vector and column vector) of the matrix of interaction estimated by ANOVA. For the same matrix, $\mathrm{D} i j$ is the non-significant effect or noise of $(g a) i j$, which is an additional residue and eij is the pooled experimental error, assumed independent and eij $\sim \mathrm{N}(0, \mathrm{~F} 2)$. In this procedure, the contribution of each genotype and each environment to the GE interaction is assessed by use of the biplot graph display in which yield means are plotted against the scores of the first principal component of the interaction (IPCA 1). The stability parameters, regression coefficient (bi) and deviation from regression $\left(\mathrm{S}^{2} \mathrm{di}\right)$ were estimated according to Eberhart and Russell (1966). Significance of differences among bi value and unity was tested by t-test, between $S^{2}$ di and zero by F-test. All the statistical analyses were done using software Crop Stat version 7.2 (AMMI, SSA and ANOVA models).

\section{RESULTS AND DISCUSSION}

The tested hybrid rice genotypes showed significant differences for plant height, days to maturity and grain yield, which indicated high genetic variability among the genotypes (Table 1). Highly significant mean sum of squares due to environments in respect of all the traits indicated that the environments were highly diverse and suitable to test for the stability of genotypes. The genotype $\mathrm{x}$ environment interactions were found significant for plant height, growth duration and grain yield indicated significant differences among the regression coefficients and that the data might be extended for stability analysis. Analysis of variance based on AMMI model for grain yield is 
presented in Table 1. The effects of genotype $\mathrm{x}$ environment interaction could be divided into four components, ie, IPCA1, IPCA2, IPCA3 and IPCA4 where IPCA2 and IPCA3 were significantly different, but IPCA1 and IPCA4 was not significantly different. G x E (linear) for grain yield have been found significant indicating linear relationship in the expression of grain yield with different environments.

Table1. Full joint analysis of variance including the partitioning of the $\mathrm{G} \times \mathrm{E}$ interaction of hybrid and inbred rice

\begin{tabular}{l|l|l|l|l}
\hline \multirow{2}{*}{ Source of variation } & df & \multicolumn{4}{c}{ Mean sum of squares } \\
\cline { 2 - 5 } & & Plant height $(\mathrm{cm})$ & Days to maturity & Grain yield (t/ha) \\
\hline Genotypes (G) & 11 & $35.553 * * *$ & $197.994 * * *$ & $5.439 * * *$ \\
Environment (E) & 4 & $255.746^{* * *}$ & $86.906 * * *$ & $0.515 * * *$ \\
Replication & 2 & $136.242^{* *}$ & $30.406 \mathrm{~ns}$ & $0.153 \mathrm{~ns}$ \\
Interaction G x E (GEI) & 44 & $11.353^{* *}$ & $4.571 * *$ & $0.871 * *$ \\
AMMI Component 1 & 14 & $24.882^{* * *}$ & $7.873 \mathrm{~ns}$ & $0.132 \mathrm{~ns}$ \\
AMMI Component 2 & 12 & $8.709 * *$ & $5.518 * *$ & $0.786 * *$ \\
AMMI Component 3 & 10 & $3.276 \mathrm{~ns}$ & $2.219 \mathrm{~ns}$ & $0.899 * *$ \\
AMMI Component 4 & 8 & $1.740 \mathrm{~ns}$ & $0.313 \mathrm{~ns}$ & $0.185 \mathrm{~ns}$ \\
G x E (Linear) & 11 & $24.102 * *$ & $6.755 \mathrm{~ns}$ & $0.807 * * *$ \\
Pool deviation & 33 & 7.104 & 3.843 & 0.893 \\
Pooled error & 88 & 17.919 & 6.988 & 0.175 \\
\hline
\end{tabular}

*** Significant at $1 \%$ level, $* *$ Significant at $5 \%$ level, ns $=$ not significant

The genotypes Richer, BRRI dhan33, Heera-2, BRRI dhan39 and Teea showed negative phenotypic index $(\mathrm{Pi})$, insignificant regression coefficient (bi) and deviation from regression $\left(\mathrm{S}^{2} \mathrm{di}\right)$ for plant height (Table 2) indicating stability of these five genotypes over all environments with semi dwarf plant stature. Dwarf variety is required to avoid lodging. BRRI hybrid dhan 4 showed negative phenotypic index $(\mathrm{Pi})$, significant regression coefficient (bi) and non significant deviation from regression $\left(\mathrm{S}^{2} \mathrm{di}\right)$ values indicating shorter plant type and highly responsive to the favorable environments at Faridpur and Jamalpur district.

For growth duration the genotypes BRRI hybrid dhan2, BRRI hybrid dhan4, Teea, Mayna, Richer and Heera2 showed negative phenotypic index (Pi), insignificant regression coefficient (bi) and deviation from regression $\left(\mathrm{S}^{2} \mathrm{di}\right)$ indicating stability of genotypes over all environments with shorter growth duration (Table 3). The hybrid, Heera995 showed the negative phenotypic index (Pi), significant regression coefficient (bi) and non significant deviation from regression $\left(\mathrm{S}^{2}\right.$ di) indicating shorter growth duration and highly responsive to the favorable environment of Rajshahi district.

The environmental mean and genotypic mean of grain yield ranged from 3.92 to 5.17 t/ha and $3.23 \mathrm{t} / \mathrm{ha}$ to $6.46 \mathrm{t} / \mathrm{ha}$, respectively (Table 5). Seven genotypes showed positive phenotypic index, while the other genotypes had negative phenotypic index for yield (Table 4). Positive phenotypic index indicated the higher yield and negative indicated the lower yield among the genotypes. Positive and negative environmental index (Ij) reflects the rich or favorable and poor or unfavorable environments for this character, respectively. The environmental index ( $\mathrm{Ij}$ ) directly reflects the poor or rich environment in terms of negative and positive $\mathrm{Ij}$, respectively. Thus the environment of Rajshahi and Faridpur location were identified as poor and Gazipur, Satkhira and Jamalpur locations was identified as rich environments for rice hybrid cultivation. 


\begin{tabular}{|c|c|c|c|c|c|c|c|c|c|c|}
\hline \multirow[t]{2}{*}{ En. No } & \multirow{2}{*}{ Pedigree } & \multicolumn{6}{|c|}{ Locations } & \multirow{2}{*}{$\begin{array}{l}\text { Phenotypic } \\
\text { Index (Pi) }\end{array}$} & \multirow{2}{*}{ bi } & \multirow{2}{*}{$\mathrm{S}^{2} \mathrm{di}$} \\
\hline & & Gazipur & Satkhira & Faridpur & Jamalpur & Rajshahi & Overall mean & & & \\
\hline 1 & BR1A/BR827R & 113.3 & 111.2 & 103.7 & 106.5 & 110.1 & 109.0 & 5.3 & 0.667 & 7.05 \\
\hline 2 & BRRI hybrid dhan1 & 107.0 & 112.1 & 95.88 & 93.67 & 111.7 & 104.1 & 0.4 & 1.824 & 7.47 \\
\hline 3 & BRRI hybrid dhan2 & 105.8 & 109.2 & 101.8 & 106.5 & 104.9 & 105.6 & 1.9 & 0.176 & 8.52 \\
\hline 4 & BRRI hybrid dhan 4 & 102.6 & 104.7 & 99.52 & 98.13 & 103.6 & 101.7 & -2.0 & $0.578 *$ & 0.86 \\
\hline 5 & Teea & 104.3 & 105.6 & 100.3 & 95.53 & 109.1 & 103.0 & -0.7 & 1.076 & 3.09 \\
\hline 6 & Mayna & 108.9 & 107.3 & 99.74 & 95.40 & 108.4 & 103.9 & 0.2 & $1.302 *$ & 0.61 \\
\hline 7 & Richer & 100.8 & 106.3 & 97.83 & 90.47 & 104.5 & 99.99 & -3.71 & 1.270 & 6.39 \\
\hline 8 & Heera-2 & 103.9 & 104.7 & 97.80 & 99.47 & 103.6 & 101.9 & -1.8 & 0.583 & 2.91 \\
\hline 9 & Heera-995 & 108.2 & 107.5 & 102.4 & 104.6 & 105.7 & 105.7 & 2.0 & $0.355^{*}$ & 3.54 \\
\hline 10 & BRRI dhan31 & 112.0 & 106.7 & 107.8 & 97.27 & 110.2 & 106.8 & 3.1 & 1.030 & 13.4 \\
\hline 11 & BRRI dhan33 & 106.2 & 101.3 & 99.71 & 86.73 & 110.0 & 100.8 & -2.9 & 1.736 & 18.8 \\
\hline \multirow[t]{5}{*}{12} & BRRI dhan39 & 107.2 & 104.7 & 100.7 & 90.73 & 106.6 & 102.0 & -1.7 & 1.401 & 5.56 \\
\hline & Mean & 106.7 & 106.8 & 100.6 & 97.08 & 107.4 & 103.7 & & & \\
\hline & Env. index (Ij) & 3.0 & 3.1 & -3.1 & -6.62 & 3.7 & & & & \\
\hline & $\mathrm{CV} \%$ & 3.96 & 3.22 & 5.09 & 4.32 & 3.70 & & & & \\
\hline & LSD (0.05) & 7.16 & 5.82 & 8.67 & 7.10 & 6.73 & & & & \\
\hline
\end{tabular}


Table 3. Stability analysis for days to maturity of hybrid and inbred rice varieties evaluated in five environments during T Aman 2008

\begin{tabular}{|c|c|c|c|c|c|c|c|c|c|c|}
\hline \multirow[t]{2}{*}{ En.No } & \multirow{2}{*}{ Pedigree } & \multicolumn{6}{|c|}{ Locations } & \multirow{2}{*}{$\begin{array}{l}\text { P. Index } \\
(\mathrm{Pi})\end{array}$} & \multirow{2}{*}{ bi } & \multirow{2}{*}{$S^{2} \mathrm{di}$} \\
\hline & & Gazipur & Satkhira & Faridpur & Jamalpur & Rajshahi & Overall mean & & & \\
\hline 1 & BRRI 1A/ BR 827R & 116.7 & 118.0 & 115.3 & 114.0 & 113.3 & 115.5 & 1.2 & 0.543 & 2.02 \\
\hline 2 & BRRI hybrid dhan 1 & 119.7 & 126.7 & 115.3 & 120.3 & 110.7 & 118.5 & 4.2 & 1.829 & 15.30 \\
\hline 3 & BRRI hybrid dhan 2 & 113.7 & 111.7 & 115.7 & 113.7 & 108.7 & 112.7 & -1.6 & 0.728 & 4.22 \\
\hline 4 & BRRI hybrid dhan 4 & 113.3 & 111.7 & 113.0 & 113.0 & 108.3 & 111.9 & -2.4 & 0.692 & 1.13 \\
\hline 5 & Teea & 110.0 & 108.0 & 108.7 & 110.7 & 104.3 & 108.3 & -6.0 & 0.778 & 2.31 \\
\hline 6 & Mayna & 112.3 & 110.7 & 111.3 & 110.7 & 106.7 & 110.3 & -4.0 & 0.758 & 0.68 \\
\hline 7 & Richer & 113.0 & 110.3 & 111.7 & 111.7 & 106.7 & 110.7 & -3.6 & 0.802 & 1.64 \\
\hline 8 & Heera-2 & 111.7 & 111.0 & 110.3 & 110.3 & 105.7 & 109.8 & -4.5 & 0.876 & 0.12 \\
\hline 9 & Heera-995 & 111.0 & 111.7 & 110.0 & 110.7 & 107.0 & 110.1 & -4.2 & $0.664 *$ & 0.15 \\
\hline 10 & BRRI dhan31 & 133.7 & 135.7 & 136.3 & 128.3 & 121.7 & 131.1 & 16.8 & 2.024 & 10.92 \\
\hline 11 & BRRI dhan33 & 114.7 & 116.0 & 113.7 & 113.3 & 109.3 & 113.4 & -0.9 & 0.902 & 0.47 \\
\hline \multirow[t]{5}{*}{12} & BRRI dhan39 & 121.0 & 122.0 & 117.3 & 121.7 & 112.3 & 118.9 & 4.6 & 1.406 & 3.33 \\
\hline & Mean & 115.9 & 116.1 & 114.9 & 114.9 & 109.6 & 114.3 & & & \\
\hline & $E$ index $(\mathrm{Ij})$ & 1.6 & 1.8 & 0.6 & 0.6 & -4.7 & & & & \\
\hline & CV \% & 1.92 & 1.77 & 2.64 & 2.71 & 2.41 & & & & \\
\hline & $\operatorname{LSD}(0.05)$ & 3.77 & 3.49 & 5.13 & 5.27 & 4.46 & & & & \\
\hline
\end{tabular}


Among the hybrids, BRRI hybrid dhan2 showed the highest yield but had significant regression coefficient (bi) and non significant deviation from regression $\left(\mathrm{S}^{2} \mathrm{di}\right)$ which meant it was not stable variety and responsive to Gazipur, Satkhira and Jamalpur locations. The promising hybrid BR1A/BR827R was high yielding as well as stable over the environments. BRRI hybrid dhan4, Mayna, Teea, Heera995 and BRRI hybrid dhan1 were highly stable with moderate yield potential.

Table 4. Stability analysis for grain yield (ton/ha) of hybrid and inbred rice varieties evaluated in five environments during T. Aman 2008 season

\begin{tabular}{|c|c|c|c|c|c|c|c|c|c|}
\hline \multirow[t]{2}{*}{ Pedigree } & \multicolumn{6}{|c|}{ Locations } & \multirow{2}{*}{$\begin{array}{c}\mathrm{P} . \\
\text { Index } \\
(\mathrm{Pi})\end{array}$} & \multirow[t]{2}{*}{ bi } & \multirow[t]{2}{*}{$\mathrm{S}^{2} \mathrm{di}$} \\
\hline & Gazipur & Satkhira & Faridpur & Jamalpur & Rajshahi & $\begin{array}{l}\text { Overall } \\
\text { mean }\end{array}$ & & & \\
\hline BR1A/ BR 827R & 6.407 & 5.667 & 5.237 & 5.667 & 5.187 & 5.633 & 1.117 & 0.875 & 0.04 \\
\hline BRRI hybrid dhan 1 & 5.700 & 4.897 & 3.873 & 4.343 & 3.933 & 4.549 & 0.033 & 1.381 & 0.07 \\
\hline BRRI hybrid dhan 2 & 6.637 & 6.683 & 6.363 & 6.413 & 6.213 & 6.462 & 1.946 & $0.317 *$ & 0.01 \\
\hline BRRI hybrid dhan 4 & 5.777 & 5.683 & 4.800 & 5.360 & 4.900 & 5.304 & 0.788 & 0.832 & 0.01 \\
\hline Teea & 5.647 & 5.463 & 4.617 & 5.500 & 4.267 & 5.099 & 0.583 & 1.078 & 0.08 \\
\hline Mayna & 5.853 & 5.390 & 4.550 & 5.507 & 4.500 & 5.160 & 0.644 & 1.119 & 0.03 \\
\hline Richer & 4.483 & 3.783 & 2.380 & 4.020 & 3.057 & 3.545 & -0.971 & 1.507 & 0.09 \\
\hline Heera-2 & 4.227 & 3.627 & 2.193 & 4.040 & 2.970 & 3.411 & -1.105 & 1.453 & 0.15 \\
\hline Heera-995 & 5.383 & 5.277 & 4.477 & 5.047 & 4.637 & 4.964 & 0.448 & 0.744 & 0.01 \\
\hline BRRI dhan31 & 4.353 & 4.140 & 3.007 & 3.070 & 2.970 & 3.508 & -1.008 & 1.125 & 0.15 \\
\hline BRRI dhan33 & 3.870 & 3.257 & 2.680 & 3.477 & 2.867 & 3.230 & -1.286 & 0.864 & 0.03 \\
\hline BRRI dhan 39 & 3.693 & 3.893 & 2.853 & 3.117 & 3.087 & 3.329 & -1.187 & 0.706 & 0.08 \\
\hline Mean & 5.169 & 4.813 & 3.919 & 4.630 & 4.049 & 4.516 & & & \\
\hline Env. index (Ij) & 0.653 & 0.297 & -0.597 & 0.114 & -0.467 & & & & \\
\hline $\mathrm{CV} \%$ & 5.38 & 6.95 & 11.46 & 6.37 & 13.5 & & & & \\
\hline LSD (0.05) & 0.47 & 0.57 & 0.76 & 0.50 & 0.89 & & & & \\
\hline
\end{tabular}

Biplot analysis is the most powerful interpretive tool for AMMI model. There are two AMMI biplots, the AMMI1 biplot where the main effects (genotype mean and environment mean) and IPCA1 scores for both genotypes and environments are plotted against each other and the AMMI2 biplot where scores for IPCA1 and IPCA2 are plotted. In AMMI biplot, the usual interpretation of a biplot assay is that if a genotype or an environment has an IPCA1 score of nearly zero, the interaction is positive, if different, their interaction is negative. The AMMI1 biplot (Fig.1) clearly indicated that all the twelve genotypes studied differed from each other and not only for mean yields, but also for their interaction effects. However, the environments studied differed only for their interaction effects and they exhibited less difference for the main effect. The genotypes BRRI hybrid dhan1, Teea, BR1A/BR827R and BRRI dhan33 had IPCA1 score near zero and hence had small interaction effects indicating that these varieties were less influenced by the environments. Among these four genotypes BR1A/BR827R and Teea were found to have above average yield. On the other hand, the variety BRRI dhan 33 gave lower yield along with the IPCA1 score close to zero, it was adjudged as the stable genotype and had of IPCA1 score for both genotype and environment implies positive interaction and then higher yield of the genotypes at that particular location.

The location Satkhira among the environments and Heera-995 and BRRI hybrid dhan 4 among the genotypes had positive IPCA1 score and registered above average yield, hence these genotypes were identified as specifically adapted to culture at the Satkhira location and this environment was considered as the suitable environment for these genotypes. BRRI hybrid dhan2 had the highest yield and larger IPCA1 scores indicated more unstable genotype over environments. The genotype Mayna and the environment of Gazipur had above average yield and negative IPCA1 score and thus the 
environment of Gazipur was found to have favorable environment for the genotype Mayna.

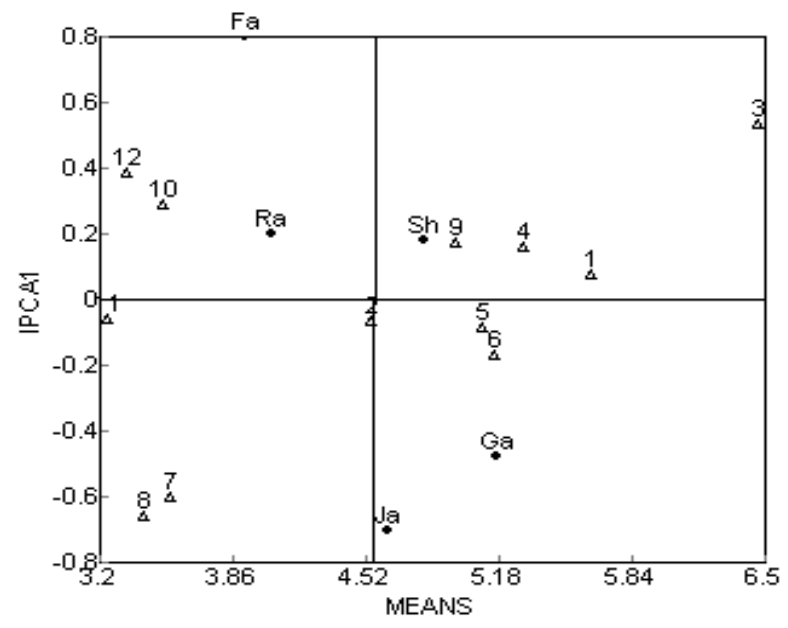

Legends: $\mathrm{Ga}=$ Gazipur, $\mathrm{Sh}=$ Satkhira, $\mathrm{Fa}=$ Faridpur, Ja=Jamalpur Ra=Rajshahi

Fig. 1: AMMI 1 biplot of main effects and $\mathrm{G} x \mathrm{E}$ interaction of 12 genotypes of rice at five environments

In AMMI2 biplot (Fig.2) the environmental scores are joined to the origin by site lines. Sites with short spokes do not exert strong interactive forces. Those with long spokes exert strong interaction. The environments of Satkhira and Rajshahi had short spokes and they did not exert strong interactive forces. The genotypes near the origin are non sensitive to environmental interaction and those distant from the origins are sensitive and have large interaction. In the present study the genotypes BRRI hybrid dhan2, Heera-2, Richer, BRRI hybrid dhan1, BRRI dhan31 and BRRI dhan39 had large interaction since they were away from the origin, where as the genotypes BR1A/BR827R, BRRI hybrid dhan4, Heera-995, Teea, BRRI dhan33 and Mayna were close to the origin and hence they were non-sensitive to environmental interactive forces.

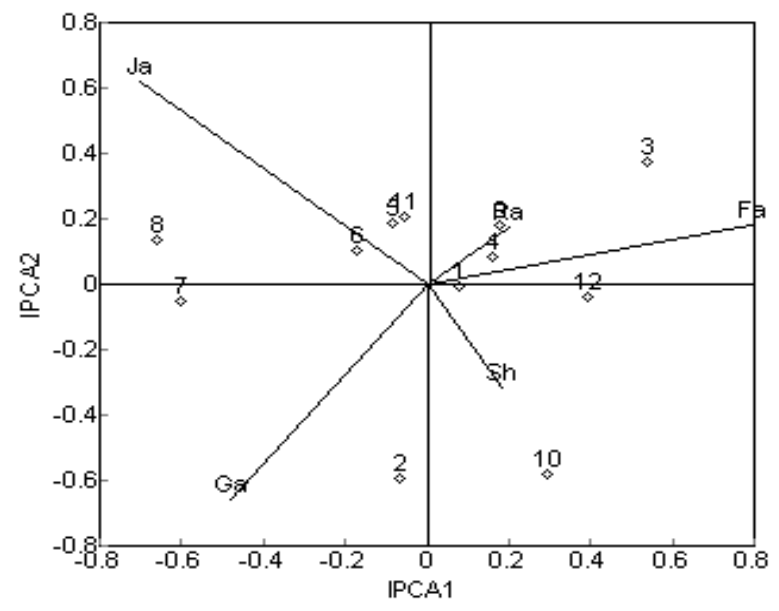

Legends: $\mathrm{Ga}=$ Gazipur, $\mathrm{Sh}=$ Satkhira, $\mathrm{Fa}=$ Faridpur, Ja=Jamalpur Ra=Rajshahi

Fig. 2: AMMI 2 biplot of $\mathrm{G} \times \mathrm{E}$ interaction of 12 rice genotypes at five environments 
Genotypes with IPCA1 scores near zero had little interaction across environments while genotypes with very high IPCA1 values had considerable interactions across environments. Among the 12 genotypes, four had negligible interactions characterized by BR1A/BR827R, BRRI hybrid dhan1, Teea and BRRI dhan33 (Table 5) and had relatively stable broad adaptation across environments. Five genotypes with higher IPCA scores were highly interactive and were unstable across environments included BRRI hybrid dhan2, Richer, Heera-2, BRRI dhan31 and BRRI dhan39. Satkhira was found more stable than Rajshahi and had the best performances for grain yield. Both the locations were relatively stable environments and highly productive for rice grain yield. Faridpur and Jamalpur location had high IPCA1 score and highly interactive with lower grain yield. In the present study, highly significant mean squares were found which indicated presence of sufficient variability among the genotypes and environments for all the studied characters. Similar results were reported by Iftekharuddaula et al.,(2002) and Khatun et al.,(2010) in rice. A significant genotype x environment interaction (GEI) for a quantitative trait reduces the usefulness of the genotype means over various locations or environments for selecting and advancing superior genotypes to the next stage of selection (Pham and Kang, 1988). Similar reports were made earlier by Dinesh Kumar (1987), Shantakumar (1997) and Mahapatra and Sujatha Das (1999) in rice varieties and Hedge (1996) and Lohithaswa et al., (1999) in rice hybrids.

Table 5. AMMI mean yield and IPCA1 scores for 12 rice genotypes grown in five environments

\begin{tabular}{lccc}
\hline \multicolumn{1}{c}{ Genotypes } & ID & AMMI mean yield (ton/ha) & IPCA1 score \\
\hline BR1A/BR27R & 1 & 5.633 & 0.080 \\
BRRI hybrid dhan 1 & 2 & 4.549 & -0.068 \\
BRRI hybrid dhan 2 & 3 & 6.462 & 0.538 \\
BRRI hybrid dhan 4 & 4 & 5.304 & 0.160 \\
Teea & 5 & 5.099 & -0.084 \\
Mayna & 6 & 5.160 & -0.170 \\
Richer & 7 & 3.545 & -0.60 \\
Heera-2 & 8 & 3.411 & -0.66 \\
Heera-995 & 9 & 4.964 & 0.176 \\
BRRI dhan31 & 10 & 3.508 & 0.293 \\
BRRI dhan33 & 11 & 3.230 & -0.055 \\
BRRI dhan39 & 12 & 3.329 & 0.390 \\
\hline Environments & & & -0.478 \\
\hline Gazipur & Ga & 5.169 & 0.184 \\
Satkhira & Sh & 4.813 & 0.797 \\
Faridpur & Fa & 3.919 & -0.702 \\
Jamalpur & $\mathrm{Ja}$ & 4.630 & 0.199 \\
Rajshahi & $\mathrm{Ra}$ & 4.049 & \\
\hline
\end{tabular}

Significant G x E (linear) for grain yield have been reported for linear relationship in the expression of grain yield with different environments (Kumar et al., 1990; Payasi and Singh, 2001; Nanitadevi et al., 2006). Dwarf plant type is desirable for hybrid rice to maintain lodging resistance. Banik et al., (2010) reported that stability of three genotypes overall environments with semi dwarf plant stature. Shorter growth duration is desirable for hybrid rice. Aditya et al., (2010) observed the genotype BRRI dhan29-SC3-28-L3 was short growth duration and stable over locations. Hossain et al., (2007) also found three genotypes viz. BR6887-25-8, BR6887-21-7-1 and BR6894-63-2- 
4 were most stable with change of environments. The grain yield was sensitive and highly influenced by environment resulting in higher $\mathrm{G} \times \mathrm{E}$ interaction under stress environments in rainfed ecosystem as reported earlier (Wade et al., 1997; Cooper et al., 1999; Ouk et al., 2007).

The AMMI statistical model has been used to diagnose the $\mathrm{G} \times \mathrm{E}$ interaction pattern of grain yield of hybrid rice. The genotypes BR1A/BR827R, BRRI hybrid dhan1, BRRI hybrid dhan4, Teea, Heera-995 and BRRI dhan33 had relatively stable performance with broad adaptation across environment. Satkhira was stable environments for all the genotypes. Gazipur was suitable for Mayna mentioned specific adaptation. BRRI hybrid dhan2 was the best in performance but more unstable over the environments.

\section{REFERENCES}

Aditya, T. L., S. Ghosal, N. Sharma, M. R. Islam, R. R. Majumder, H. Khatun, R. Bhuiyan, F.M. Moinuddin, B. Karmakar and T.H. Ansari. 2010. General and specific adaptability through genotype-environment interactions of some somaclonal lines in rice. Bangladesh J. Prog. Sci. Tech. 8(1): 5-8.

Banik, B. R., A. B. M. Khaldun, A. A. Mondal, A. Islam and M. M. Rohman 2010. Assessment of Genotype-by-environment interaction using additive main effects and multiplicative interaction model (AMMI) in maize (Zea mays L.) hybrids. Acad. J. Plant Sci. 3: 134-139.

Cooper, M., D. W. Podlich and S. Fukai 1999. Combining information from multienvironment trials and molecular markers to select adaptive traits for yield improvement of rice in water limited environments. In: Genetic Improvement of Rice for Water Limited Environments, Ed. Ito. O, O’ Toole. J. and Hardy, B., Int. Rice Res Inst, Philippines, pp.13-34.

Dinesh Kumar, V. 1987. Stability analysis of yield components in early maturing genotypes of rice (Oryza sativa L.). M.Sc. (Agri.) thesis, University of Agricultural Science, Bangalore. pp.81-85.

Eberhart, S. A. and W. A. Russel 1966. Stability parameters for comparing varieties. Crop Sci. 6: 36-40.

Hegde, S. 1996. Stability analysis in rice (Oryza sativa L.) hybrids. M.Sc. (Agri.) thesis, University of Agricultural Science, Bangalore. pp.67-70.

Hossain, M. A., K. M. Akhter, M. A. Salam, M. Khatun and M. E. Hoque. 2007. Yield stability of some T. Aus rice genotypes. Bangladesh J. Prog. Sci. Tech. 5(1): 173176.

Iftekharuddaula, K. M., Khaleda Akter, M. S. Hasan and M. A. Badshah. 2002. Genotype-Environment Interaction in Irrigated Rice in Bangladesh. Thai. J. Agril. Sci. 35(3): 229-236.

Khatun, M., T. L. Aditya, M. A. Rahman, K. M. Iftekharuddaula and M. A. Salam. 2010. Stability analysis of premium quality rice genotypes (Oryza sativa L.). Intl. J. BioRes. 8(2): 1-5.

Kumar, R., A. K. Yadav and I. S. Yadav. 1990. Maturity traits and those predictions through genotype $\mathrm{x}$ environment interactions in Oleiferous Brassicae. J. Oilseed Res. 7(1): 21-25.

Laxmi, R. R. and R. Gupta. 2000. Different approaches for stability measures in relation to genotype-environment interaction. Crop Res. 20(1): 118-125.

Lin, C. S., M. R. Bains and L. P. Lefkovitvh. 1986. Stability analysis: Where do we stand? Crop Sci. 26: 894-900. 
Lohithaswa, H. C., D. Bhushan, Basavarajaiah, H. C. Prasanna and R. S. Kulkarni. 1999. Stability analysis in rice (Oryza sativa L.) hybrids. Karnataka J. Agril. Sci. 12: 4854.

Mahapatra, K.C. and Sujatha Das. 1999. Stability of yield in relation to component traits in rice. Oryza. 36: 301-305.

Nanitadevi, M., N. B. Shing, M. R. K. Shing and P. R. Sharma. 2006. Stability analysis of selected rice genotypes at varying spacing and sowing dates under rainfed low land condition in Manipur valley. Oryza. 43: 14-20.

Ouk, M., J. Basnayake, M. Tsubo, S. Fukai, K. S. Fischer, S. Kang, S. Men, V. Thun and M. Cooper. 2007. Genotype-by-environment interactions for grain yield associated with water ability at flowering in rainfed low land rice. Field Crops Res. 101: 145154.

Payasi, S. K. and A. K. Singh. 2001. Stability for disease resistance, yield and yield attributes in rice. Crop Res. Hisar. 21(2): 188-191.

Pham, H. N. and M. S. Kang. 1988. Interrelationships among and repeatability of several stability statistics estimated from international maize trials. Crop Sci. 28: 925-928.

Piepho, H. P 1999. Stability analysis using the SAS system. Agron. J. 91: 154-160.

Shantakumar, G 1997. Genotype environment interaction references to cold tolerance. M.Sc. (Agri.) thesis, University of Agricultural Science, Bangalore. pp.81.

Wade, L. J., C. G. McLaren, L. Criseno, S. T. Amarante, A. K.Warawgi, R. Kumar, M. C. Bhamri, O. N. Shing, H. U. Ahmed, S. Rajatasereeku, S. P. Pomurai, C. Boonwite, D. Harnpichivitaya and S. Sarkarung. 1997. Genotype-by-environment interactions: RLRRC Experience In: Breeding Strategies for Rainfed Lowland Rice in Drought-prone Environments. Edts. Fukai, S., Cooper, M. and Salisbury, J., Int Rice Res Inst, Philippines, pp.115-125.

Zobel, R. W., M. J.Wright and H. G. Gauch. 1998. Statistical analysis of a yield trial. Agron. J. 80: 388-393. 